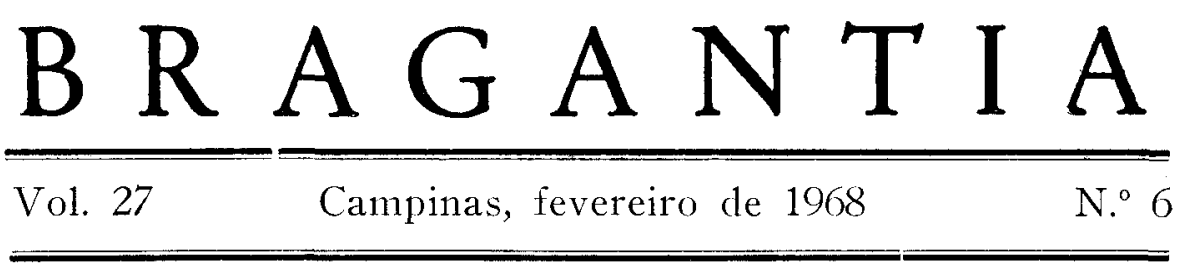

\title{
EFEITO DO ESPAÇAMENTO ENTRE BULBOS NA PRODUÇÃO DE SEMENTES DE CEBOLA ( $\left.{ }^{1}{ }^{2}\right)$
}

Humberto Ribeiro de Campos, Dr. Leocádio de Souza Camargo, engenheiros-agrônomos, Seção de Olericultura, e EduARdo ABRAMIdes, engenheiro-agrônomo, Seção de Técnica Experimental, Instituto Agronômico

\section{SINOPSE}

Ensaio de campo foi conduzido em solo latossolo vermelho-amarelo fase argilosa, série Barão, para estudar o efeito do espaçamento dos bulbos de cebola (Allium cepa L.), visando a produção de sementes. Compararam-se quatro espaçamentos em que os bulbos de cebola, na linha de plantio, foram distanciados entre si de $40 \mathrm{~cm}, 30 \mathrm{~cm}, 20 \mathrm{~cm}$ e $10 \mathrm{~cm}$.

O espaçamento menor, de $10 \mathrm{~cm}$ entre os bulbos, superou os demais em produção de sementes por área. Como implica na diminuição da área para um mesmo número de bulbos a serem plantados e em menor gasto de adubos e de água para irrigação torna-se ainda mais vantajoso.

\section{1 - INTRODUÇÃO}

O Estado de São Paulo é tradicional produtor de bulbos de cebola; até há poucos anos, porém, as sementes utilizadas nas suas lavouras eram oriundas do Estado do Rio Grande do Sul e de outros países, principalmente Estados Unidos.

Segundo dados fornecidos pelo Departamento de Defesa Sanitária Vegetal, do Ministério da Agricultura, entraram pelo pôrto de Santos, nos anos de 1960,1961 e 1962 , respectivamente, $18,4,9,9$ e 17,2 toneladas de sementes de cebola.

O Estado de São Paulo iniciou a produção de sementes de cebola em escala comercial, em 1965, em campos de cooperação da Divisão de Sementes e Mudas, da Secretaria da Agricultura.

(1) A FAl'ESP colaborou na obtenção dos dados experimentais, Recebirlo para publicação em r.o de setembro de I967.

(2) Trabalho apresentado na VII Reunião Anual da Sociedade de Olericultura do Bra* sil, realizada no Rio de Janeiro, Guanabara, no período de 9 a 15 de julho de ig67. 
Knott (2) diz que o espaçamento para a plantação de bulbos com a finalidade de produção de sementes deve ser de $90 \mathrm{~cm}$ entre as linhas, enquanto que nestas os bulbos são colocados encostados um ao lado do outro.

Não existindo dados técnicos sôbre espaçamento para produção de sementes de cebola a serem aplicados às condições do planalto paulista procurou-se esclarecer êste assunto (1).

\section{2 - MATERIAL E MÉTODO}

Este ensaio foi montado na Estação Experimental «Theodureto de Camargo», Campinas, no local denominado Ponte Sêca, cujo solo é do tipo latossolo vermelho-amarelo fase argilosa, série Barão. Antes do plantio foi retirada amostra de terra, cuja análise, efettuada pela Seção de Fertilidade do Solo, é a seguinte:

pH int. - 5,10; Carbono \%- 1,96; $\mathrm{PO}_{4}{ }^{\cdots}$ e.mg - 0,26; $\mathrm{K}+$ e.mg - 0,40; $\mathrm{Ca}++\mathrm{Mg}++$ e.mg - 2,80; $\mathrm{Al}+++$ e.mg - traços.

Usou-se o delineamento de blocos ao acaso com seis repetições. Os canteiros possuiam 2,40 $\mathrm{m}$ de comprimento e 4,80 m de largura. Os bulbos foram plantados em quatro linhas. As duas linhas internas se achavam a $80 \mathrm{~cm}$ uma da outra. A distância de cada linha interna até a externa foi de $2,00 \mathrm{~m}$.

Utilizou-se, para o ensaio, de bulbos da variedade Monte Alegre IAC-3335, do tipo de segunda, cujo diâmetro transversal variava entre 40 e 55 milimetros.

Foram comparados quatro espaçamentos entre os bulbos, na linha de plantio, a saber: 40,30, 20 e 10 centímetros. Nessas condições, o número de bulbos foi variável para cada tratamento, sendo de 24,32 , 48 e 96 bulbos por canteiro, respectivamente para os espaçamentos de $40,30,20$ e 10 centímetros. Na mesma ordem, o pêso dos bulbos por canteito foi de $1.573,2.116,2.943$ e 5.556 gramas.

A adubação, igual para todos os tratamentos, efetuada 10 dias antes do plantio, foi a seguinte por metro linear: 
Composto ................... 5 quilogramas

Superfosfato $\left(20 \% \quad \mathrm{P}_{2} \mathrm{O}_{5}\right) \ldots \ldots \ldots \ldots \ldots \ldots$ gramas

Cloreto de potássio $\left(60 \%\right.$ de $\left.\mathrm{K}_{2} \mathrm{O}\right) \ldots \ldots .20$ gramas

Sulfato de amônio $(20 \% \mathrm{~N}) \quad \ldots \ldots \ldots \ldots .40$ gramas

O sulfato de amônio foi aplicado em cobertura aos 30 e 45 dias após o plantio, usando-se 20 gramas em cada aplicação.

O plantio dos bulbos foi efetuado em 4 de maio de 1966, e as colheitas de sementes foram realizadas no período de 14 a 26 de outubro do mesmo ano, para todos os tratamentos.

\section{3 - RESULTAdOS E DISCUSSÃO}

Os resultados médios, obtidos por tratamento, encontram-se no quadio 1 .

Quadro 1. - Produção de sementes por canteiro, produção de sementes por metro quadrado, produção de sementes por planta, relação entre o pêso total de bulbos e sementes colhidas, obtida em ensaio de espaçamento entre bulbos para produção de sementes de cebola.

\begin{tabular}{|c|c|c|c|c|}
\hline \multirow[b]{2}{*}{$\begin{array}{c}\text { Espaçamento } \\
\text { entre } \\
\text { bulbos }\end{array}$} & \multicolumn{3}{|c|}{ Produção de sementes } & \multirow{2}{*}{$\begin{array}{c}\text { Relação entre } \\
\text { o pêso total } \\
\text { de bulbos e } \\
\text { sementes } \\
\text { colhidas }\end{array}$} \\
\hline & $\begin{array}{c}\text { Por } \\
\text { canteiro } \\
\left(11,52 \mathrm{~m}^{2}\right)\end{array}$ & $\begin{array}{c}\text { Por } \\
\text { metro } \\
\text { quadrado }\end{array}$ & $\begin{array}{l}\text { Por } \\
\text { planta }\end{array}$ & \\
\hline & $(g)$ & (g) & $(g)$ & $(\%)$ \\
\hline$A-40 \mathrm{~cm} \ldots$ & 435 & 37,7 & 18,1 & 27,6 \\
\hline$B-30 \mathrm{~cm} \ldots$ & 630 & 54,6 & 19,6 & 29,7 \\
\hline$C-20 \mathrm{~cm} \ldots$ & 803 & 69,7 & 16,7 & 27,2 \\
\hline$D-10 \mathrm{~cm} .$. & 1.128 & 97,9 & 11,7 & 20,3 \\
\hline
\end{tabular}

Com um coeficiente de variação de $17,4 \%$, a análise da variância revelou diferenças significativas entre os tratamentos. A diferença mínima significativa entre duas médias, pelo teste de Tukey ao nível de $5 \%$, foi de 217 gramas.

Observando-se o quadro 1 , nota-se que o tratamento $D(10 \mathrm{~cm}$ cntre bulbos) apresenta reais vantagens sobre os demais, tais como:

1) Sensivel aumento de produção de sementes por área. 
2) Diminuição de área para um mesmo número de bulbos a serem plantados e, em conseqüência, sensível diminuição no gasto de adubos.

3) Diminuição no consumo de água para irrigação, menor tempo gasto nessa operação e economia de mão de obra para os traltos culturais e pulverizações.

\section{4 - CONCLUSÕES}

Nas condições do presente ensaio podem ser tiradas as seguintes conclusões :

1) Foi obtida maior produção de sementes por área, quando os bulbos foram plantados distanciados de $10 \mathrm{~cm}$ na linha, ou seja, pràticamente encostados um ao outro.

2) Há diminuição de área para um mesmo número de bulbos a serem plantados e conseqüentemente menor gasto de adubos, menor consumo de água para irrigação e economia de mão de obra.

\section{EFFECT OF SPACING BETWEEN BULBS IN THE PRODUCTION OF ONION SEEDS}

\section{SUMMARY}

This paper reports the results of a spacing experiment with bulbs of onion (Allium cepa L.) where production of seed was considered.

Four spacings were compared in a line, i.e., a) $40 \mathrm{~cm}$; b) $30 \mathrm{~cm}$; c) $20 \mathrm{~cm}$ and d) $10 \mathrm{~cm}$.

The spacing of $10 \mathrm{~cm}$ between bulbs showed to be superior to the others in seed production by area. Some other advantages of this spacing are that less space is needed for the same number of bulbs to be planted and that less expenses are incurred in fertilizers, irrigation water and workmanship.

\section{LITERATURA CITADA}

1. CAMP'OS, H. R.; CAMARGO, L. S. \& ABRAMIDES, E. Produção de sementes de cebola: ensaio de espaçamento. In: Relatório anual da Seção de Olericultura do Instituto Agronômico, 1966. (Não publicado)

2. KNOTT, J. E. Cebola. In: Palestras sôbre horticultura, proferidas na Escola Superior de Agricultura "Luiz de Queiroz". São Paulo, Universidade, 1951. fls.62-63. 